\title{
Tricuspid regurgitation is uncommon after mitral valve repair for degenerative diseases
}

\author{
Tirone E. David, MD, Carolyn M. David, BN, Chun-Po S. Fan, PhD, and Cedric Manlhiot, PhD
}

\section{ABSTRACT}

Objective: To determine the incidence and effects of tricuspid regurgitation (TR) after surgery for mitral valve (MV) repair for mitral regurgitation (MR) due to degenerative disease.

Patients and Methods: We examined 1171 patients who had MV repair and were followed prospectively with periodical clinical and echocardiographic assessments during a mean of $9.1 \pm 5.3$ years. Patients' mean age was $58.2 \pm 12.7$ years, and $70.5 \%$ were men. Preoperatively, $44.6 \%$ were in functional classes III and IV, $20.1 \%$ had atrial fibrillation, and $34.2 \%$ had ejection fraction $<60 \%$. In addition to MV repair, $13.8 \%$ had coronary artery bypass, $11.4 \%$ had the maze procedure, and $4.7 \%$ had tricuspid annuloplasty.

Results: Moderate and severe TR was present in 138 patients before surgery and associated with older age, preoperative atrial fibrillation, preoperative congestive heart failure, congenital heart septal defects, lower preoperative left ventricular ejection fraction, and female sex by multivariable analysis. TR resolved postoperatively but recurrent or new isolated TR occurred in 45 patients postoperatively (13.6\% at 15 years in all patients). Factors associated with isolated postoperative TR by multivariable analysis included older age at operation, unrepaired preoperative moderate/severe TR, and the development of postoperative MR. Patients with preoperative TR had reduced long-term survival and tricuspid annuloplasty did not restore lifespan.

Conclusions: Preoperative TR in patients with MR due to degenerative diseases was associated with longstanding MV disease and adversely affected long-term survival after MV repair. New postoperative TR was uncommon. The findings of this study are compelling reasons to repair the MV before the development of TR. (J Thorac Cardiovasc Surg 2017;154:110-22)

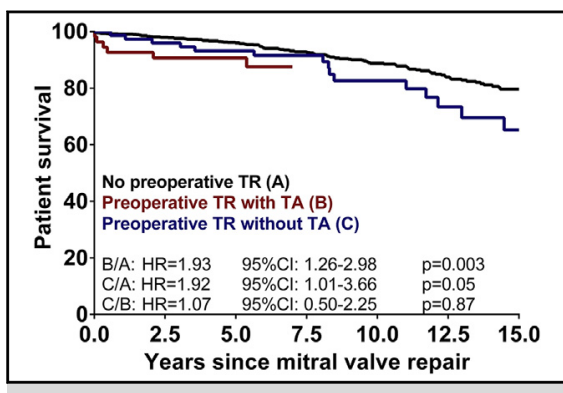

Patients' survival after mitral valve repair.

\section{Central Message}

Functional tricuspid regurgitation after mitral valve repair for degenerative diseases of the mitral valve was uncommon in this long-term study.

\section{Perspective}

Functional tricuspid regurgitation in patients with mitral regurgitation due to degenerative diseases was associated with older age, chronic atrial fibrillation, advanced functional class, congenital heart defects, impaired left ventricular function, and female sex. These factors adversely affected long-term survival after valve repair and concomitant tricuspid annuloplasty did not restore lifespan.

See Editorial Commentaries pages 123 and 125 .

See Editorial page 108.
This study was prompted by a presentation by Joanna Chikwe at the 2015 Annual Meeting of The American Association for Thoracic Surgery (AATS) in Seattle, where she reported on a series of 645 patients who had mitral valve (MV) repair for degenerative disease and $419(65 \%)$ of

\footnotetext{
From the Division of Cardiovascular Surgery of Peter Munk Cardiac Centre at Toronto General Hospital and University of Toronto, Toronto, Ontario, Canada.

This project was funded by the Academic Enrichment Fund of the Division of Cardiovascular Surgery of Toronto General Hospital and partially funded by a generous grant from Anthony and Miranda Wong.

Read at the 96th Annual Meeting of The American Association for Thoracic Surgery, May 14-18, 2016, Baltimore, Maryland.

Received for publication May 18, 2016; revisions received Nov 30, 2016; accepted for publication Dec 16, 2016; available ahead of print March 2, 2017.

Address for reprints: Tirone E. David, MD, 200 Elizabeth St 4N453, Toronto, Ontario M5G 2C4, Canada (E-mail: tirone.david@uhn.ca).

$0022-5223 / \$ 36.00$

Copyright (c) 2017 by The American Association for Thoracic Surgery

http://dx.doi.org/10.1016/j.jtcvs.2016.12.046
}

them had concomitant tricuspid annuloplasty (TA) because of moderate tricuspid regurgitation (TR), tricuspid annular diameter $\geq 40 \mathrm{~mm}$ by echocardiography, or direct inspection of the tricuspid valve (TV) in equivocal cases. Because $83 \%$ of the patients who TA had mild, trace, or no TR, the mean diameter of the tricuspid annulus was $38.8 \mathrm{~mm}$, and more than one half of all patients had advanced myxomatous degeneration of the MV (which often involves the TV too), we argued that the rate of TA

Scanning this QR code will take you to the supplemental table for this article. To view the AATS 2016 Webcast, see the URL next to the video thumbnail.

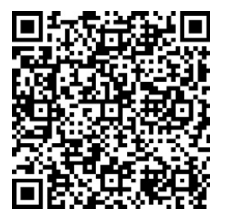




$$
\begin{aligned}
& \text { Abbreviations and Acronyms } \\
& \begin{aligned}
\text { AATS }= & \text { American Association for Thoracic } \\
& \text { Surgery } \\
\text { AF }= & \text { atrial fibrillation } \\
\mathrm{CI}= & \text { confidence interval } \\
\mathrm{HR}= & \text { heart ratio } \\
\mathrm{MR}= & \text { mitral regurgitation } \\
\mathrm{MV}= & \text { mitral valve } \\
\mathrm{OR}= & \text { odds ratio } \\
\mathrm{TA}= & \text { tricuspid annuloplasty } \\
\mathrm{TR}= & \text { tricuspid regurgitation } \\
\mathrm{TV}= & \text { tricuspid valve }
\end{aligned}
\end{aligned}
$$

was excessively high and unnecessary. Robert Dion clearly disagreed with our views and gave the indications when TA should be combined with MV surgery in a recent editorial. ${ }^{2}$ A brief review of our data confirmed our views expressed at the AATS meeting. ${ }^{3}$ In another editorial in the Journal, Richard Shemin put things in perspective and correctly stated that we need more evidence and less personal opinions on issues as perplexing as functional TR. ${ }^{4}$

This study examined the incidence of $\mathrm{TR}$ and its consequences in a large cohort of patients who had MV repair for mitral regurgitation (MR) due to degenerative diseases during the last 3 decades. When we first began a program of MV repair for MR in mid-1980s, we overlooked the TV unless the right side of the heart was dilated grossly at surgery or the patient had had evidence of right-side heart failure preoperatively because we believed that the TR would resolve after correction of the left-side lesion. Moreover, in reviewing the echocardiographic reports from studies done in the 1980s and 1990s, we found that the TV also was overlooked frequently by the echocardiographers because their written reports contained no information on the functional status of this valve or simply stated that the right-sided valves were normal without quantification of TR. We observed, however, that a few patients developed transient right-side failure during the first weeks after MV repair and that these patients often had echocardiographic evidence of moderate or severe TR before surgery; as a result, we increased the rate of TAs we performed over time.

\section{PATIENTS AND METHODS}

Isolated MV repair for MR due to degenerative diseases of the MV was performed in 1171 patients by one surgeon from 1985 to 2010. The clinical outcomes of MV repair on these patients were published recently in 2 separate reports, but the issue of concomitant TR was not addressed. ${ }^{5,6}$ We used the database from those 2 reports to design this study. Our patients were followed by the referring cardiologists, and both patients and cardiologists were contacted by our research personnel periodically (yearly during the first 2-3 years and approximately every 2-3 years thereafter), and an echocardiogram was requested to assess MV and ventricular function.

The echocardiograms were read by various cardiologists, who sent us a written report. Valve regurgitation was recorded as none, trivial, mild, moderate, and severe (if a report read "mild to moderate," it was counted as moderate and if read "moderate to severe," it was counted as "severe") and entered in a dedicated database. Most echocardiographic reports from 1980s and early 1990s had detailed information on the aortic and MVs but scant information on TV, and sometimes read "normal right-side valves." In 119 patients who had no preoperative echocardiographic data on the TV, we used the TR grading obtained in the operating room (transepicardial echocardiography in the first couple of years of the study and transesophageal since 1988). Postoperative studies that reported the TV as "normal" but contained no information of the severity TR were excluded from analysis. Since the publication of the guidelines by American Society of Echocardiography in 2003, all reports contained detailed information on all 4 heart valves. ${ }^{7}$ The diameter of the tricuspid annulus was only sporadically measured and not entered in the datasets.

Adverse events were reported according to the guidelines set by cardiac surgical societies. ${ }^{8}$ The cause of death was determined by hospital chart review, death certificates, or information from the physician who was caring for the patient at that time. Clinical follow-up was complete in $98.1 \%$ (defined as patient having a terminal event or being contacted within 2 years from our previous reports on MV repair ${ }^{5,6}$ ). Echocardiography was performed in all patients in the operating room and before discharge from hospital. Echocardiographic data were available in $95.7 \%$ of patients alive at the last follow-up. The overall mean follow-up was $9.1 \pm 5.3$ years, but it was shorter at $6.9 \pm 4.9$ years for patients who had TA combined with MV repair for the aforementioned reasons. Twelve patients with TR had leaflet prolapse and were included in the group as functional TR. This study was approved by the Review Ethics Board of the University Health Network and patients' consent waived.

\section{Statistical Analysis}

Data are presented as means with standard deviation, median with interquartile range (25th and 75th percentile), and frequencies as appropriate Comparisons of patients' clinical profile and perioperative outcomes (Tables 1 and 2) were performed by either the Fisher exact test, Wilcoxon 2-sample test, or Student $t$ test assuming unequal variance between groups, as appropriate. Visual inspection of the distribution for continuous variables was used to assess normality. Factors associated with preoperative moderate/severe TR and undergoing concomitant TA were modeled with a logistic regression models (see below for model building strategy). Recognizing that patients included in this study were at risk of multiple postoperative outcomes at the same time, a nonparametric competing risk model was developed. In this model, patients could transition to 1 of 5 possible endpoints, whichever occurred first. These endpoints are listed to follow, with the remaining of the patients being alive and free from reoperation or moderate/severe MR or TR:

- reoperation for isolated MR;

- reoperation for isolated TR;

- reoperation for concomitant MR/TR

- reoperation for reasons other than MR or TR; or

- death before reoperation.

Cox proportional hazard was used to identify factors associated with postoperative mortality. For both the binary and time-dependent outcomes, the strategy for model building was similar. For the first time, outcomespecific univariable regression models were used to screen potential risk factors (Table E1), and risk factors with univariable $P$ values $<.20$ were then included in a bootstrap resampling algorithm (1000 random resamples). Variables with a high reliability (ie, selection in $>50 \%$ of the samples) were then included in a multivariable regression models with backward selection of variables to obtain a final model. TR over time was modeled with the use of longitudinal mixed models, with backward selection of variables that were statistically significant at the univariable level to obtain a final model. Mean imputation was used for 
TABLE 1. Patients' clinical profiles

\begin{tabular}{|c|c|c|c|c|}
\hline Variable & All patients & MV repair & MV + TV repair & $P$ value \\
\hline Number of patients & 1171 & 1116 & 55 & \\
\hline Age at surgery, $y$, average \pm SD & $58.2 \pm 12.7$ & $57.9 \pm 12.6$ & $65.5 \pm 13.4$ & $<.001$ \\
\hline Sex (male) & $826(70.5)$ & $798(71.5)$ & $28(50.9)$ & .002 \\
\hline Previous surgical cardiac intervention & $22(1.9)$ & $20(1.8)$ & $2(3.6)$ & .28 \\
\hline Urgent operation & $84(7.3)$ & $78(7.2)$ & $6(10.9)$ & .66 \\
\hline NYHA class & & & & $<.001$ \\
\hline Class I & $224(19.1)$ & $220(19.7)$ & $4(7.3)$ & .02 \\
\hline Class II & $437(37.3)$ & $426(38.2)$ & $11(20.0)$ & .007 \\
\hline Class III & $412(35.2)$ & $384(34.4)$ & $28(50.9)$ & .01 \\
\hline Class IV & $98(8.4)$ & $86(7.7)$ & $12(21.8)$ & .001 \\
\hline Left ventricular ejection fraction & & & & $<.001$ \\
\hline$\geq 60 \%$ & $771(65.8)$ & $751(67.2)$ & $20(37)$ & $<.001$ \\
\hline $40 \%-59 \%$ & $349(29.8)$ & $322(28.9)$ & $27(50)$ & .002 \\
\hline $20 \%-39 \%$ & $50(4.3)$ & $43(3.9)$ & $7(13)$ & $<.001$ \\
\hline$<20 \%$ & $1(0.1)$ & $1(0.1)$ & 0 & $>.99$ \\
\hline Atrial fibrillation or flutter & $235(20.1)$ & $206(18.5)$ & $29(52.7)$ & $<.001$ \\
\hline Complete heart block & $12(1.0)$ & $7(0.6)$ & $5(9.1)$ & $<.001$ \\
\hline History of congestive heart failure & $539(46.0)$ & $495(44.4)$ & $44(80.0)$ & $<.001$ \\
\hline \multicolumn{5}{|l|}{ Associated diseases } \\
\hline Diabetes & $50(4.3)$ & $48(4.3)$ & $2(3.6)$ & $>.99$ \\
\hline Hypertension & $344(29.4)$ & $330(29.6)$ & $14(25.5)$ & .65 \\
\hline Hyperlipidemia & $282(24.1)$ & $270(24.2)$ & $12(21.8)$ & .75 \\
\hline Family history of coronary artery disease & $445(38.9)$ & $434(39)$ & $20(36.4)$ & .78 \\
\hline Smoking & $508(43.5)$ & $478(43)$ & $30(54.6)$ & .10 \\
\hline Chronic obstructive lung disease $\left(\mathrm{FEV}_{1}<1\right)$ & $34(2.9)$ & $33(3)$ & $1(1.8)$ & $>.99$ \\
\hline Previous stroke/transient ischemic attack & $63(5.4)$ & $58(5.2)$ & $5(9.1)$ & .22 \\
\hline Peripheral vascular disease & $8(0.7)$ & $8(0.7)$ & 0 & $>.99$ \\
\hline Marfan syndrome & $16(2)$ & $16(2.1)$ & 0 & $>.99$ \\
\hline Renal failure & $3(0.3)$ & $3(0.3)$ & 0 & $>.99$ \\
\hline Creatinine $>150 \mu \mathrm{mol} / \mathrm{L}$ & $6(0.7)$ & $6(0.7)$ & 0 & $>.99$ \\
\hline \multicolumn{5}{|l|}{ Infective endocarditis } \\
\hline Active & $5(0.4)$ & $5(0.5)$ & 0 & $>.99$ \\
\hline Remote & $95(8.1)$ & $91(8.2)$ & $4(7.3)$ & .80 \\
\hline Congenital heart defects (ASD, VSD) & $36(3.1)$ & $30(2.7)$ & $6(10.9)$ & .005 \\
\hline Ascending aorta dilatation & $11(0.9)$ & $9(0.8)$ & $2(3.6)$ & .09 \\
\hline Coronary artery disease & $162(13.8)$ & $155(13.9)$ & $7(12.7)$ & .64 \\
\hline \multicolumn{5}{|l|}{ Echocardiographic data } \\
\hline TV regurgitation & & & & $<.001$ \\
\hline None/trivial & $513(43.8)$ & $513(45.9)$ & 0 & $<.001$ \\
\hline Mild & $520(44.4)$ & $520(46.6)$ & 0 & $<.001$ \\
\hline Moderate & $99(8.4)$ & $73(6.5)$ & $26(47.3)$ & $<.001$ \\
\hline Severe & $39(3.3)$ & $10(0.9)$ & $29(52.7)$ & $<.001$ \\
\hline Tricuspid valve pathology & & & & $<.001$ \\
\hline Functional tricuspid regurgitation & $102(8.7)$ & $59(5.2)$ & $43(78.1)$ & $<.001$ \\
\hline Tricuspid regurgitation with leaflet prolapse & $12(1)$ & 0 & $12(20.8)$ & $<.001$ \\
\hline Mitral regurgitation & & & & $>.99$ \\
\hline Moderate & $62(5.3)$ & $59(5.2)$ & $3(4.9)$ & $>.99$ \\
\hline Severe & $1009(94.7)$ & $1057(94.7)$ & $52(95)$ & $>.99$ \\
\hline \multicolumn{5}{|l|}{ MV prolapse } \\
\hline None (annular dilatation) & $18(1.5)$ & $15(1.3)$ & $3(4.9)$ & .06 \\
\hline Posterior leaflet & $460(39.2)$ & $438(39.2)$ & $22(40)$ & .05 \\
\hline Anterior leaflet & $214(18.2)$ & $208(18.4)$ & $6(10.9)$ & .21 \\
\hline Bileaflet & $479(40.9)$ & $455(40.7)$ & $24(43.6)$ & $>.99$ \\
\hline
\end{tabular}


TABLE 1. Continued

\begin{tabular}{|c|c|c|c|c|}
\hline Variable & All patients & MV repair & MV + TV repair & $P$ value \\
\hline \multicolumn{5}{|l|}{ MV pathology } \\
\hline Advanced myxomatous degeneration & $254(21.7)$ & $245(21.9)$ & $9(16.3)$ & .93 \\
\hline Dystrophic calcification of the mitral annulus & $32(2.7)$ & $30(2.7)$ & $2(3.6)$ & $>.99$ \\
\hline \multicolumn{5}{|l|}{ Operative data } \\
\hline MV repair & $1171(100)$ & $1116(100)$ & $55(100)$ & $>.99$ \\
\hline Mitral annulus reconstruction & $32(2.7)$ & $30(2.7)$ & $2(3.6)$ & $>.99$ \\
\hline \multicolumn{5}{|l|}{ Mitral annuloplasty } \\
\hline Carpentier ring & $101(8.6)$ & $98(8.7)$ & $3(5.4)$ & .62 \\
\hline Duran ring & $152(12.9)$ & $145(13)$ & $7(12.7)$ & $>.99$ \\
\hline Cosgrove band & $509(43.4)$ & $490(43.9)$ & $19(34.6)$ & .17 \\
\hline Simplici-T band & $337(28.8)$ & $312(28)$ & $25(45.5)$ & .009 \\
\hline No ring & $72(6.2 \%)$ & $71(6.4)$ & $1(1.8)$ & .25 \\
\hline \multicolumn{5}{|l|}{ Tricuspid annuloplasty } \\
\hline DeVega & - & - & $28(50.9)$ & \\
\hline Simplici-T band & - & - & $22(40)$ & \\
\hline Carpentier ring & - & - & $5(9)$ & \\
\hline Closure of atrial or ventricular septal defects & $36(3.1)$ & $30(2)$ & $6(10.9)$ & .005 \\
\hline Ascending aorta replacement & $11(0.9)$ & $9(0.8)$ & $2(3.6)$ & .09 \\
\hline Maze procedure & $133(11.4)$ & $111(10)$ & $22(40)$ & $<.001$ \\
\hline Coronary artery bypass graft & $162(13.8)$ & $155(13.9)$ & $7(12.7)$ & .64 \\
\hline Cardiopulmonary bypass time, min & $82 \pm 26$ & $81 \pm 25$ & $107 \pm 29$ & $<.001$ \\
\hline Aortic clamping time, $\min$ & $65 \pm 23$ & $64 \pm 22$ & $84 \pm 23$ & $<.001$ \\
\hline
\end{tabular}

Percentages are shown in parentheses. $M V$, Mitral valve; $T V$, tricuspid valve; $S D$, standard deviation; $N Y H A$, New York Heart Association; $F E V_{l}$, forced expiratory volume per second; $A S D$, atrial septal defect; VSD, ventricular septal defect.

the rare missing data points in potential predictor variables. All statistical analyses were performed with SAS v9.3 (SAS Institute, Cary, NC).

\section{RESULTS}

\section{Preoperative and Intraoperative Characteristics and Perioperative Outcomes}

A total of 1171 patients were included in this study, of whom $1116(95.3 \%)$ underwent isolated MV repair and $55(4.7 \%)$ underwent combined MV repair and TA. Table 1 shows the clinical profile and operations performed in all patients and stratified by whether the patient underwent concomitant TA. Table 2 shows the perioperative outcomes. Before surgery, $99(8.5 \%)$ patients had moderate TR, and $39(3.3 \%)$ had severe TR. All patients who underwent TA had moderate or severe TR preoperatively. Factors associated with preoperative moderate or severe TR are listed in Table 3 and included preoperative atrial fibrillation (AF), older age at operation, advanced functional class/congestive heart failure, congenital heart disease, lower preoperative ejection fraction, and female sex. Interestingly, odds of preoperative TR were not associated with year of surgery either in univariable analyses (odds ratio [OR], 0.98/year, 95\% confidence interval $[95 \% \mathrm{CI}], 0.96-1.01, P=.24)$ or when added to the multivariable model described previously (OR, 1.02/year, 95\% CI, 0.99-1.05, $P=.26$ ).

Not all patients who had moderate or severe preoperative TR had concomitant TA, and as shown in Figure 1, and the probability of undergoing concomitant TA in those patients increased with later year of surgery (hazard ratio [HR], 1.10/year, 95\% CI, 1.04-1.16, $P<.001$ ), indicating increasing awareness of a potential TR problem over time. In addition to year of operation, other factors associated with undergoing concomitant TA are listed in Table 4. Those factors included greater preoperative TR grade, lower preoperative ejection fraction, congenital heart septal disease, greater preoperative functional class, and older age at operation. Early postoperative outcome stratified by isolated MV repair versus MV repair with concomitant TA are listed in Table 2 and showed an expectedly worsened postoperative profile in patients with concomitant MV repair and TA.

\section{Long-Term Outcomes}

Figure 2 shows long-term competing outcomes separately for all patients (upper panel), for patients without or with moderate/severe preoperative TR or concomitant TA (middle and lower panels respectively). Prevalence at various time points of all competing outcomes over time since initial surgery is listed in Table 5 . There were 6 early and 178 late deaths: 82 valve or cardiac-related, 93 noncardiac or valvular, and 3 unknown causes. The operative mortality was greater in patients who had TA $(0.4 \%$ vs $3.6 \%, P=.03)$. There were $43(3.7 \%)$ reoperations for recurrent MR (38 patients) or MR with TR (5 patients) but no reoperation for isolated TR, although 
TABLE 2. Perioperative outcomes

\begin{tabular}{|c|c|c|c|c|}
\hline & All patients & MV repair & MV + TV repair & $P$ value \\
\hline Ventilation time, h, median (25th-75th) & $5(4-7)$ & $5(4-7)$ & $7(5-11)$ & .04 \\
\hline ICU stay, h, median (25th-75th) & $24(21-42)$ & $24(21-28)$ & $46(24-74)$ & .002 \\
\hline Hospital stay, d, median (25th-75th) & $7(6-9)$ & $7(6-9)$ & $8(7-11)$ & .03 \\
\hline Intra- or postoperative IABP & $14(1.2)$ & $10(0.9)$ & $4(7.3)$ & .003 \\
\hline \multicolumn{5}{|l|}{ Reoperations } \\
\hline Any reoperation & $56(4.8)$ & $54(4.8)$ & $2(3.6)$ & $>.99$ \\
\hline Bleeding/tamponade & $49(4.2)$ & $48(5.4)$ & $1(1.8)$ & .72 \\
\hline Shock/arrest + bleeding & 1 & 1 & 0 & $>.99$ \\
\hline Sternal infection & 1 & 1 & 0 & $>.99$ \\
\hline Sternal dehiscence & 1 & 1 & 0 & $>.99$ \\
\hline Redo mitral valve surgery & 2 & 1 & 1 & .09 \\
\hline Other & $2(0.2)$ & $2(0.2)$ & 0 & $>.99$ \\
\hline Perioperative myocardial infarction & $7(0.6)$ & $7(0.6)$ & 0 & $>.99$ \\
\hline Low output syndrome & $39(3.3)$ & $33(3.0)$ & $6(10.9)$ & .008 \\
\hline Dialysis required & $4(0.3)$ & $4(0.4)$ & 0 & $>.99$ \\
\hline Insertion of permanent pacemaker & $39(3.3)$ & $32(2.9)$ & $7(12.7)$ & .002 \\
\hline New postoperative atrial fibrillation & $239(20.4)$ & $232(20.8)$ & $7(12.7)$ & .17 \\
\hline Pulmonary complications & $113(9.7)$ & $108(9.7)$ & $5(9.1)$ & $>.99$ \\
\hline Seizures & $9(0.8)$ & $9(0.8)$ & 0 & $>.99$ \\
\hline Transient ischemic attack & $6(0.5)$ & $6(0.5)$ & 0 & $>.99$ \\
\hline Stroke & $7(0.6)$ & $7(0.6)$ & 0 & $>.99$ \\
\hline Sepsis & $4(0.3)$ & $4(0.4)$ & 0 & $>.99$ \\
\hline Operative mortality & $6(0.5)$ & $4(0.4)$ & $2(3.6)$ & .03 \\
\hline
\end{tabular}

$M V$, Mitral valve; $T V$, tricuspid valve; $I C U$, intensive care unit; $I A B P$, intra-aortic balloon pump.

severe TR was the principal cause of death in 2 elderly patients deemed "inoperable." A total of 10 patients had reoperation for reasons other than MR or TR.

Multivariable factors associated with postoperative mortality are listed in Table 6 and included older age at surgery, early year of operation, lower LV grade, preoperative hypertension, preoperative $\mathrm{AF}$, postoperative $(<1$ month) AF, and postoperative $(<1$ month) pacemaker implantation. Removing the 2 postoperative risk factors from the model did not add or remove any preoperative risk factors from the final model. Interestingly, the presence of TR preoperatively was associated with increased odds of mortality in univariable analyses (HR, 1.99, 95\% CI, $1.37-2.89, P<.001)$ but failed to meet the reliability

TABLE 3. Multivariable factors associated with preoperative moderate/severe tricuspid valve regurgitation

\begin{tabular}{lccc}
\hline \multicolumn{1}{c}{ Factor } & Reliability & M.OR (LCL-UCL) & $\begin{array}{c}\boldsymbol{P} \\
\text { value }\end{array}$ \\
\hline Preoperative atrial fibrillation & $99.0 \%$ & $2.444(1.589-3.761)$ & $<.001$ \\
Age at operation (per 5 y) & $98.6 \%$ & $1.200(1.093-1.319)$ & $<.001$ \\
Advanced functional class/CHF & $94.0 \%$ & $2.051(1.280-3.287)$ & .003 \\
Congenital heart disease & $93.2 \%$ & $5.114(2.139-12.23)$ & $<.001$ \\
Preoperative LVEF (per level) & $82.2 \%$ & $1.585(1.142-2.201)$ & .006 \\
Sex = female & $70.4 \%$ & $1.599(1.060-2.412)$ & .03 \\
\hline
\end{tabular}

M.OR, Multivariable odds ratio; $L C L$, lower confidence limit (95\%); UCL, upper confidence limit (95\%); $C H F$, congestive heart failure; $L V E F$, left ventricular ejection fraction. threshold of 50\% (reliability: $24.6 \%$ ) and did not reach statistical significance when added to the multivariable model described previously (HR, 1.19, 95\% CI, $0.81-1.76, P=.38$ ).

\section{Incidence of Factors and Outcomes Associated with Postoperative TR}

The development of TR after MV repair in patients without preoperative TR was rare. Moderate preoperative TR resolved in all but 3 patients and in 8 of 10 with severe

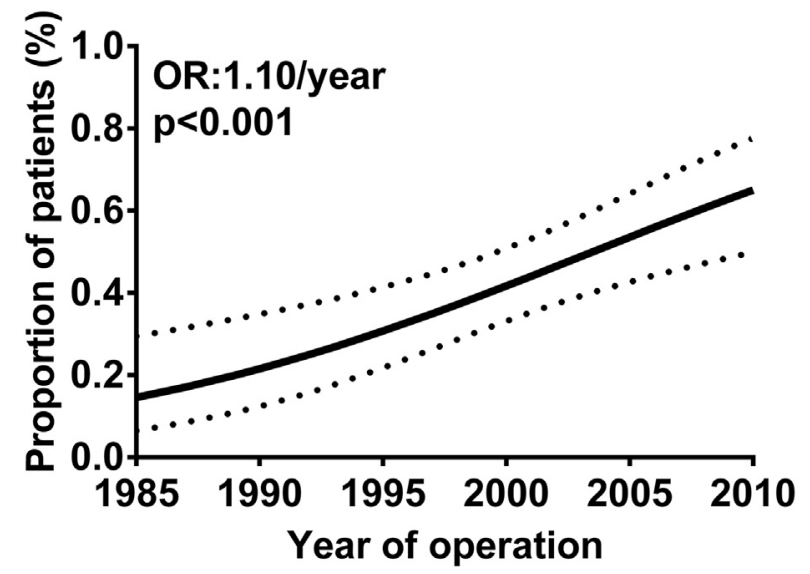

FIGURE 1. Increased probability of tricuspid annuloplasty over the years in patients with moderate and severe tricuspid regurgitation. $O R$, Odds ratio. 
TABLE 4. Multivariable factors associated with concomitant tricuspid annuloplasty

\begin{tabular}{|c|c|c|c|}
\hline Factor & Reliability & M.OR (LCL-UCL) & $P$ value \\
\hline $\begin{array}{l}\text { Preoperative TR } \\
\text { grade - per grade }\end{array}$ & $100.0 \%$ & $6.123(4.062-9.229)$ & $<.001$ \\
\hline Year of operation & $100.0 \%$ & $1.149(1.088-1.214)$ & $<.001$ \\
\hline $\begin{array}{l}\text { Preoperative LV } \\
\text { grade - per class }\end{array}$ & $98.6 \%$ & $2.610(1.559-4.369)$ & $<.001$ \\
\hline Congenital heart disease & $73.6 \%$ & $5.135(1.429-18.45)$ & .01 \\
\hline $\begin{array}{l}\text { Preoperative NYHA - per } \\
\text { class }\end{array}$ & $72.4 \%$ & $1.689(1.056-2.700)$ & .03 \\
\hline Age at operation (per 5 y) & $65.2 \%$ & $1.181(1.009-1.382)$ & .04 \\
\hline
\end{tabular}

preoperative TR, but 15 developed TR again during the follow-up. The incidence of moderate/severe TR over time is reported in Figure 3 with point estimates at 1, 5, 10, and 15 years and is provided in Table 7 along with stratification by preoperative TR and TA. Of note, $<5 \%$ of postoperative TR was in the severe range. Factors associated with isolated postoperative TR by multivariable analysis are shown in Table 8 and included older age at operation, unrepaired preoperative moderate/severe TR, and the development of postoperative MR.

\section{Impact of Performing TA in Patients With \\ Preoperative Moderate-Severe TR on Long-Term Outcomes}

Moderate or severe preoperative TR was associated with an increased risk of postoperative mortality, but performance of TA did not reduce the risk (Figure 4). Eleven patients who had TA developed recurrent moderate TR during the follow-up (7 had had DeVega annuloplasty, 3 Simplici-T band, and 1 Carpentier ring).

\section{DISCUSSION}

This study examined the incidence and effect of TR in a large cohort of patients who had MV repair for degenerative diseases. TR was addressed infrequently during the first half of this experience and only patients with evidence of right-side failure had TA. As we became more aware of $\mathrm{TR}$, we began to correct TR at the time of MV repair with a consequent increase in the number of TA over time, as documented in Figure 1 and Table 4. We found that moderate or severe TR at the time of MV repair for degenerative diseases of the MV was associated with older age, impaired left ventricular function, AF, more advanced symptoms of congestive heart failure, congenital heart septal defects, and female sex by multivariable analysis (Table 3). This study showed that these patients probably should have TA at the time of MV repair but long-term survival is reduced because of the associated risk factors rather than the presence of TR. This is another compelling
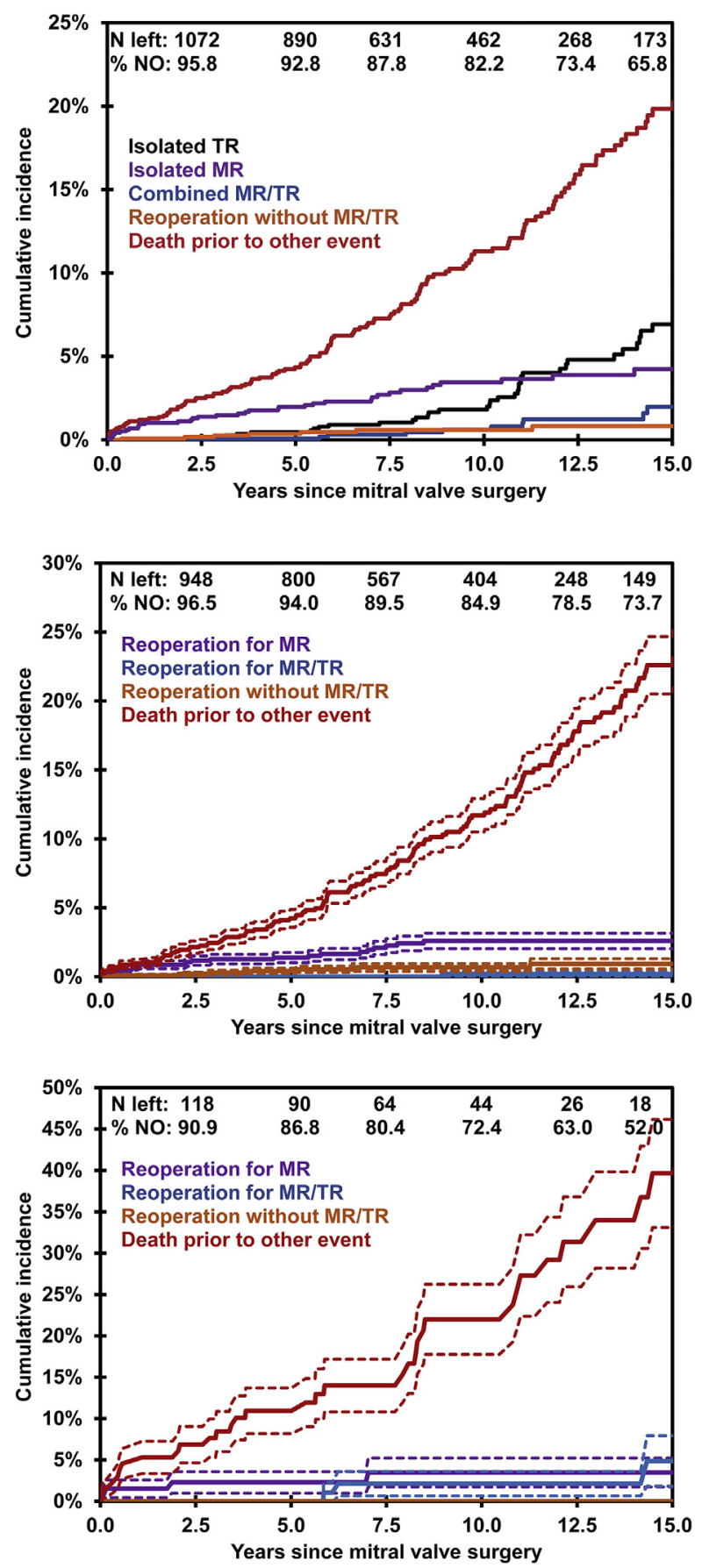

FIGURE 2. Nonparametric prevalence of competing outcomes over time after mitral valve repair. Upper panel represents outcomes for the entire cohort, middle panel represents outcomes for patients without tricuspid regurgitation, and lower panel represents patients with preoperative moderate or severe tricuspid regurgitation, respectively. Dashed lines represent the standard error around the cumulative estimate incidence. $N$ left, Number of patients at risk; \% $N O$, percent alive and free from any adverse event; $T R$, tricuspid regurgitation; $M R$, mitral regurgitation.

reason to correct MR before patients develop advanced symptoms of heart failure, left ventricular dysfunction, or AF. 
TABLE 5. Prevalence (with standard error) of outcomes in competing risk models stratified by preoperative tricuspid valve status and concomitant TA

\begin{tabular}{|c|c|c|c|c|c|c|}
\hline All patients & $\begin{array}{c}\text { Recurrent } \\
\text { Isolated MR }\end{array}$ & $\begin{array}{c}\text { Recurrent } \\
\text { Isolated TR }\end{array}$ & Recurrent MR/TR & $\begin{array}{c}\text { Reoperation } \\
\text { no MR/TR }\end{array}$ & $\begin{array}{c}\text { Death without } \\
\text { reoperation or MR/TR }\end{array}$ & $\begin{array}{c}\text { Alive, no reoperation, } \\
\text { no MR/TR }\end{array}$ \\
\hline \multicolumn{7}{|l|}{ All patients } \\
\hline $\mathrm{n}$ & 38 & 45 & 11 & 10 & 160 & 907 \\
\hline $1 \mathrm{y}$ & $1.0 \pm 0.3$ & $0.1 \pm 0.1$ & $0.1 \pm 0.1$ & $0.1 \pm 0.1$ & $1.2 \pm 0.3$ & $97.5 \pm 0.5$ \\
\hline $5 \mathrm{y}$ & $2.0 \pm 0.4$ & $0.5 \pm 0.2$ & $0.1 \pm 0.1$ & $0.4 \pm 0.2$ & $4.3 \pm 0.6$ & $92.8 \pm 0.8$ \\
\hline $10 \mathrm{y}$ & $3.4 \pm 0.6$ & $1.8 \pm 0.5$ & $0.6 \pm 0.3$ & $0.6 \pm 0.2$ & $11.3 \pm 1.1$ & $82.2 \pm 1.3$ \\
\hline $15 \mathrm{y}$ & $4.2 \pm 0.8$ & $6.9 \pm 1.2$ & $2.0 \pm 0.7$ & $0.8 \pm 0.3$ & $20.3 \pm 1.8$ & $65.8 \pm 2.2$ \\
\hline \multicolumn{7}{|c|}{ Patients without preoperative TR or concomitant TA } \\
\hline $\mathrm{n}$ & 33 & 31 & 5 & 9 & 136 & 825 \\
\hline $1 \mathrm{y}$ & $1.0 \pm 0.3$ & $0.1 \pm 0.1$ & $0.0 \pm 0.0$ & $0.1 \pm 0.1$ & $0.9 \pm 0.3$ & $98.0 \pm 0.4$ \\
\hline $5 y$ & $1.9 \pm 0.4$ & $0.2 \pm 0.1$ & $0.0 \pm 0.0$ & $0.4 \pm 0.2$ & $3.9 \pm 0.6$ & $93.6 \pm 0.8$ \\
\hline $10 \mathrm{y}$ & $3.4 \pm 0.6$ & $1.3 \pm 0.5$ & $0.2 \pm 0.2$ & $0.7 \pm 0.3$ & $10.8 \pm 1.2$ & $83.5 \pm 1.4$ \\
\hline $15 \mathrm{y}$ & $3.9 \pm 0.7$ & $5.8 \pm 1.3$ & $0.9 \pm 0.4$ & $0.9 \pm 0.4$ & $19.5 \pm 1.9$ & $68.9 \pm 2.3$ \\
\hline \multicolumn{7}{|c|}{ Patients with preoperative TR or concomitant TA } \\
\hline $\mathrm{n}$ & 5 & 14 & 6 & 1 & 24 & 82 \\
\hline $1 \mathrm{y}$ & $1.5 \pm 1.1$ & $0.0 \pm 0.0$ & $0.8 \pm 0.8$ & - & $3.8 \pm 1.7$ & $93.9 \pm 2.1$ \\
\hline $5 \mathrm{y}$ & $2.3 \pm 1.3$ & $2.5 \pm 1.4$ & $0.8 \pm 0.8$ & - & $7.7 \pm 2.3$ & $86.8 \pm 3.0$ \\
\hline $10 \mathrm{y}$ & $3.4 \pm 1.7$ & $7.1 \pm 2.6$ & $4.1 \pm 2.0$ & - & $14.9 \pm 3.6$ & $70.5 \pm 4.7$ \\
\hline $15 \mathrm{y}$ & $5.8 \pm 2.9$ & $14.9 \pm 4.5$ & $8.8 \pm 3.8$ & - & $25.3 \pm 5.4$ & $45.1 \pm 6.7$ \\
\hline
\end{tabular}

$M R$, Mitral regurgitation; $T R$, tricuspid regurgitation.

As we stated during the discussion of the paper by Chikwe and colleagues ${ }^{1}$ at the AATS meeting in 2015, the development of isolated TR after MV repair for degenerative disease was uncommon in our patients, and it was associated with advanced age at operation, unrepaired preoperative moderate/severe TR, and the development of postoperative MR as shown in Table 6. Forty-five patients developed isolated moderate or severe TR after MV repair, but 11 of them had had TA. In addition, 11 patients developed recurrent severe MR and moderate or severe TR. The estimated risk of developing isolated moderate or severe TR was $13.6 \%$ at 15 years after MV repair in all patients. In the study by Chikwe and colleagues, ${ }^{1}$ TR occurred in $9 \%$ of patients who did not have TA and in $3 \%$ of those who did only 5 years after surgery.

Murashita and colleagues ${ }^{9}$ reported an incidence of TR similar to ours after MV repair for degenerative diseases in a cohort of 479 patients who were followed for a mean of 7.5 years. They found that AF and the grade of TR before

TABLE 6. Multivariable factors associated with postoperative isolated moderate/severe tricuspid valve regurgitation

\begin{tabular}{lccc}
\hline \multicolumn{1}{c}{ Factor } & Reliability & M.HR (LCL-UCL) & $\boldsymbol{P}$ value \\
\hline Age at operation (per 5 y) & $99.8 \%$ & $1.487(1.239-1.786)$ & $<.001$ \\
$\begin{array}{l}\text { Postoperative (<1 mo) } \\
\quad \text { TR grade }\end{array}$ & $98.2 \%$ & $2.842(1.815-4.448)$ & $<.001$ \\
$\begin{array}{l}\text { Insertion of permanent } \\
\text { pacemaker }\end{array}$ & $95.4 \%$ & $7.428(3.066-18.00)$ & $<.001$ \\
$\begin{array}{l}\text { Preoperative atrial fibrillation } \\
\text { M.HR, Multivariable hazard ratio; } L C L, \text { lower confidence limit }(95 \%) ; U C L, \text { upper } \\
\text { confidence limit }(95 \%) ; T R \text {, tricuspid regurgitation. }\end{array}$ &
\end{tabular}

surgery were associated with the development of severe TR late postoperatively. This finding endorses the performance of TA in patients with moderate or severe TR. Yilmaz and colleagues ${ }^{10}$ from the Mayo Clinic examined the outcomes of 693 patients who had isolated MV repair for MR due to MV prolapse and $16 \%$ had moderate or severe TR before surgery. They excluded patients with coronary artery disease and congenital heart defects. They observed a significant reduction in the overall grade of TR within the first 3 years but a slight increase after 5 years. Female sex, preoperative AF, and diabetes mellitus were independent risk factors for increased TR with time. ${ }^{10} \mathrm{~A}$ more recent evaluation of this issue at that institution confirmed that MV repair as well as MV replacement reduced TR grade postoperatively and the development of new TR was uncommon. ${ }^{11}$

Although the number of patients who developed severe TR after MV repair was low in our study (less than $5 \%$ of recurrent TR was greater than moderate), the effect of severe TR was devastating, with a high rate of mortality at 1 year after diagnosis, which usually was made during an episode of heart failure. Topilsky and colleagues ${ }^{12}$ from the Mayo Clinic examined the outcomes of 353 patients (mean age 70 years) with isolated TR and found that an effective regurgitant orifice $\geq 40 \mathrm{~mm}^{2}$ was associated with marked reduction in survival independent of all characteristics, right ventricular size or function, comorbidity, or pulmonary pressure and lower than expected in the general population. Other investigators have found that severe TR after implantation of transvenous pacemaker was associated with poor long-term survival. ${ }^{13}$ 

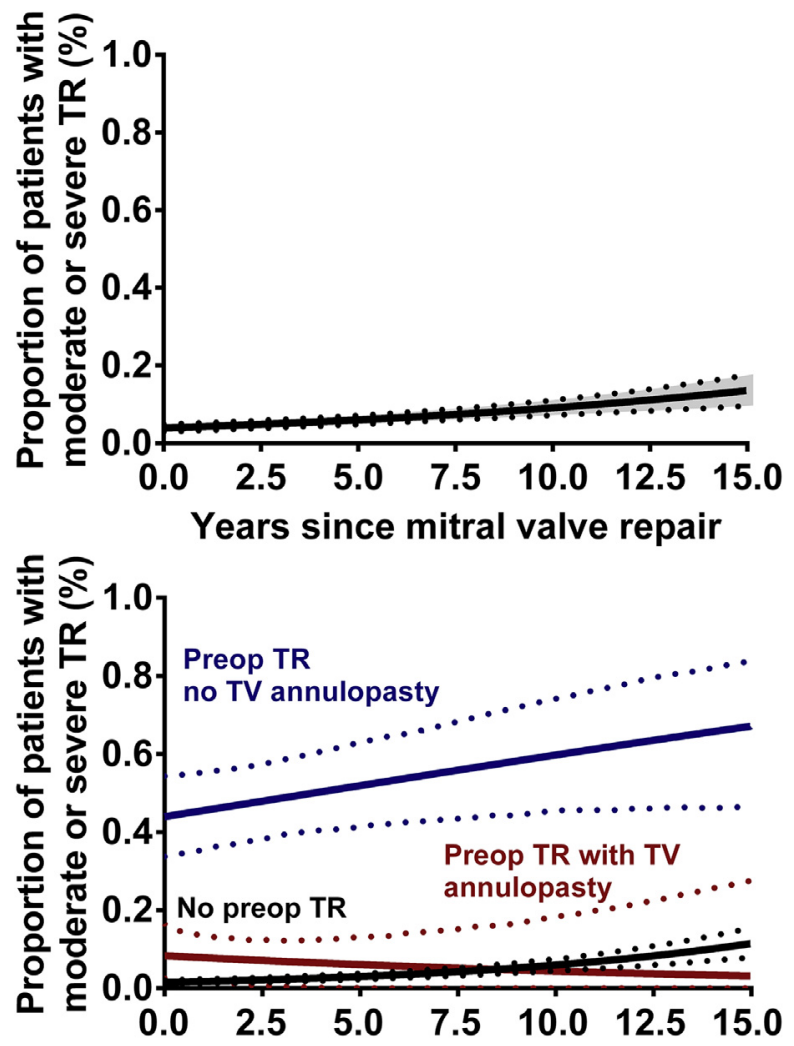

FIGURE 3. Incidence of moderate/severe tricuspid regurgitation over time for all patients (top) and stratified by preoperative tricuspid valve regurgitation and concomitant tricuspid annuloplasty (bottom). Dotted lines represent the $95 \%$ confidence interval. $T R$, Tricuspid regurgitation; Preop, preoperative; $T V$, tricuspid valve.

It is worth mentioning that insertion of permanent transvenous pacemaker after TA does not seem to increase the risk of TR. ${ }^{14}$

We have been performing the maze procedure for $\mathrm{AF}$ only since 1996 and that is the reason why only 133 of 235 with AF at the time of surgery had combined MV repair with maze. We could not establish a relationship between maze and postoperative TR, but it has been suggested that the maze procedure reduces the risk of postoperative TR if successful in eliminating $\mathrm{AF} .{ }^{15}$

Dreyfus and colleagues ${ }^{16}$ introduced the concept that annular dilatation precedes the development of TR and a tricuspid annulus $\geq 70 \mathrm{~mm}$ in the arrested heart (the distance from the commissure between septal and anterior leaflets to the base of the posterior leaflet) should be an indication for TA regardless of TR grade. Nemoto and colleagues ${ }^{17}$ examined a large number of patients with no or trace TR, mild TR, and moderate or severe TR by echocardiography and computed tomography and found TV annular dilatation and atrial enlargement comprise early events in mild functional TR and atrial enlargement occurs before right ventricular dilation, which occurs late, when TR is severe. They concluded that atrial volume and TV annular dilatation are early and sensitive indicators of TR. ${ }^{17}$ The shape of the tricuspid annulus changed from elliptical to circular with severe TR. ${ }^{17}$

This study supports the concept that tricuspid annulus dilatation may precede functional TR. The European guidelines on the management of functional TR suggests that a preoperative echocardiographic TV annulus $\geq 40 \mathrm{~mm}$ is an indication for TA (class IIa, level C). ${ }^{18}$ Several surgeons have incorporated this recommendation into their practice, and the rate of TA at the time of MV repair has soared to as high $65 \%$. $^{1,2,19,20}$ These investigators argued that the right ventricle remodels after TA in patients with dilated tricuspid annulus. ${ }^{1,19}$ The assessment of right ventricular size and function, however, is difficult and often inaccurate. ${ }^{21}$ Moreover, a recently published echocardiographic study Sordelli and colleagues $^{22}$ from Milan, Italy, which included 3-dimensional imaging, failed to show a correlation between the diameters of the TV annulus (anteroposterior and septolateral) and the development of TR after MV repair for degenerative diseases, and the authors concluded that "newly developed significant TR is a rare event after successful repair of degenerative MR."

Based on our findings, postoperative functional TR is uncommon after MV repair for degenerative diseases, and we have identified factors associated with its development except for the role of the diameter of the TV annulus. Approximately $22 \%$ of our patients had advanced myxomatous degeneration with voluminous MV leaflets and large annulus, and these patients frequently also have voluminous tricuspid leaflets. Thus, a single measurement of $40 \mathrm{~mm}$ as the cut-off point of dilated TV annulus is probably inappropriate. It may be too large for patients with small TV leaflets such as in patients with MR due to fibroelastic deficiency and too small for patients with MR due to advanced myxomatous degeneration. We believe

TABLE 7. Incidence of TR (moderate) over time (note: $<\mathbf{5} \%$ of all TR was greater than moderate)

\begin{tabular}{lcccc}
\hline Years & Overall & No preoperative TR & $\begin{array}{c}\text { Preoperative TR without } \\
\text { tricuspid annuloplasty }\end{array}$ & $\begin{array}{c}\text { Preoperative TR with } \\
\text { tricuspid annuloplasty }\end{array}$ \\
\hline 1 & $4.3 \%(3.3 \%, 5.3 \%)$ & $1.7 \%(1.2 \%, 2.3 \%)$ & $45.5 \%(35.5 \%, 55.4 \%)$ & $7.8 \%(1.9 \%, 13.5 \%)$ \\
5 & $6.0 \%(4.9 \%, 7.1 \%)$ & $3.0 \%(2.2 \%, 3.8 \%)$ & $51.9 \%(41.4 \%, 63.0 \%)$ & $6.1 \%(0.1 \%, 13.2 \%)$ \\
10 & $9.1 \%(7.2 \%, 11.1 \%)$ & $5.9 \%(4.4 \%, 7.4 \%)$ & $59.8 \%(45.5 \%, 74.1 \%)$ & $4.4 \%(0.0 \%, 18.3 \%)$ \\
15 & $13.6 \%(9.6 \%, 17.5 \%)$ & $11.5 \%(7.9 \%, 15.4 \%)$ & $67.1 \%(46.4 \%, 83.8 \%)$ & $3.1 \%(0.0 \%, 27.7 \%)$ \\
\hline
\end{tabular}

Numbers in parentheses show $95 \%$ confidence interval. $T R$, Tricuspid regurgitation. 
TABLE 8. Multivariable factors associated with recurrent TR

\begin{tabular}{lcc}
\hline \multicolumn{1}{c}{ Factor } & M.HR (LCL-UCL) & $\boldsymbol{P}$ value \\
\hline Age at operation (per 10 y) & $2.13(1.64-2.92)$ & $<.001$ \\
Preoperative TR/TA & Reference & \\
No TR & $2.96(0.92-9.19)$ & .06 \\
TR with TA & $98.3(39.7-344.4)$ & $<.001$ \\
TR without TA & & \\
Postoperative MR grade* & $0.20(0.10-0.35)$ & $<.001$ \\
\hline Less than moderate &
\end{tabular}

$T R$, Tricuspid regurgitation; $M . H R$, multivariable hazard ratio; $L C L$, lower confidence limit $(95 \%)$; UCL, upper confidence limit $(95 \%)$; TA, tricuspid annuloplasty; $M R$, mitral regurgitation. *Collected longitudinally.

that further studies are needed to define the implications of TV annular dilatation.

Finally, TA is associated with recurrent TR in a relatively high proportion of patients as documented in this study, but we and others have shown that the type of TA is an important determinant of recurrent $\mathrm{TR}$, and rigid rings and bands provide more durable repair than suture annuloplasty. $^{23,24}$

\section{Limitations of the Study}

As with most retrospective studies, this one has several limitations. Patients operated on during the first decade of this experience did not have detailed echocardiographic reports on the TV. Echocardiographic studies were performed in multiple laboratories, and we used the written report to enter postoperative MR and TR grades into our database. Together, these 2 points raise the possibility that we have underestimated the prevalence of TR both preoperatively and in the postoperative period in this study. In addition, although this study provides a unique long-term perspective on outcomes after MV repair, an era effect cannot be excluded through

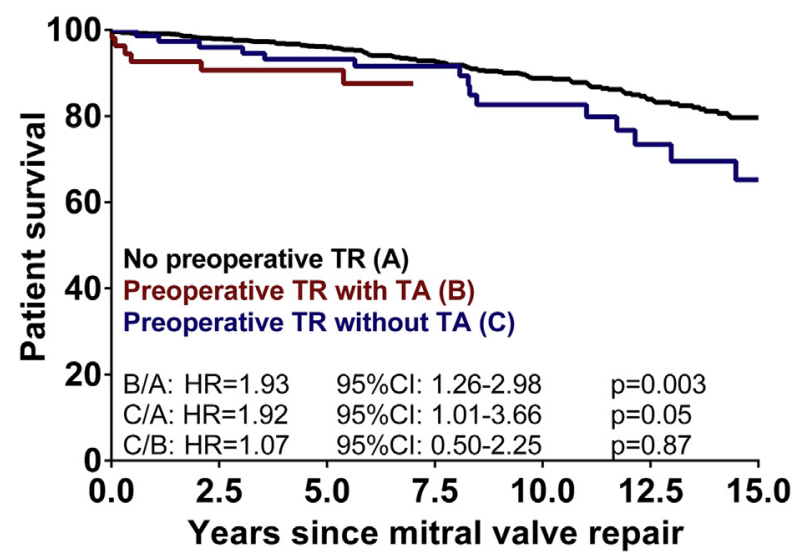

FIGURE 4. Survival over time stratified by preoperative tricuspid valve regurgitation and concomitant TA. $T R$, Tricuspid regurgitation; $T A$, tricuspid annuloplasty; $H R$, hazard ratio; $C I$, confidence interval. which risk factors once considered important no longer are and newly identified risk factors might have an effect that was not taken in account in the current study. We had no data on heart rhythm before the day of surgery or postoperatively until in the latter parts of the follow-up, preventing us from better defining the role of postoperative $\mathrm{AF}$ as well as the maze procedure in the development of TR. Finally, we must acknowledge that the patient population examined represents the practice of one surgeon. Our statistical analyses attempted to risk adjust within the unique context of our patient population, but we make no claims regarding the generalizability of those risk models to the wider patient population either clinically or statistically.

\section{CONCLUSIONS}

Patients with MR due to degenerative diseases develop TR because of older age, chronic AF, advanced functional class, impaired left ventricular function, congenital heart septal defects, and female sex. These factors adversely affect long-term survival, and TA does not seem to restore life span to the level of patients without TR. Patients with moderate and severe TR at the time of MV repair probably should have concomitant TA to reduce the probability of developing TR. New TR after MV repair is uncommon during the first 15 years of follow-up, but when it happens it is associated with poor prognosis largely because of the factors associated with it. The findings of this study are compelling reasons to recommend MV repair early on the course of severe MR due to degenerative diseases.

\section{Webcast}

You can watch a Webcast of this AATS meeting presentation by going to: http://webcast.aats.org/2016/ Video/Monday/05-16-16_Hall_E_0730_David-800.mp4.

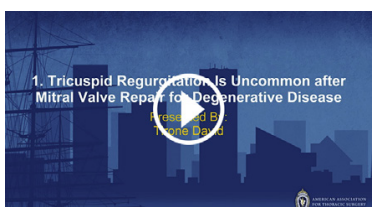

\section{Conflict of Interest Statement}

Authors have nothing to disclose with regard to commercial support.

\section{References}

1. Chikwe J, Itagaki S, Anyanwu A, Adams DH. Impact of concomitant tricuspid annuloplasty on tricuspid regurgitation, right ventricular function, and pulmonary artery hypertension after repair of mitral valve prolapse. J Am Coll Cardiol. 2015:65:1931-8.

2. Dion RA. Is the air in Toronto, Rochester, and Cleveland different from that in London, Monaco, Leiden, Genk, Milan, and New York? J Thorac Cardiovasc Surg. 2015;150:1040-3. 
3. David TE, David CM, Manhiolt C. When is tricuspid valve annuloplasty necessary during mitral valve surgery? J Thorac Cardiovasc Surg. 2015;150:1043-4.

4. Shemin RJ. Expert opinion is often hot air: it is not the air; it is the clinical evidence. J Thorac Cardiovasc Surg. 2015;150:1045-6.

5. David TE, Armstrong S, McCrindle BW, Manlhiot C. Late outcomes of mitral valve repair for mitral regurgitation due to degenerative disease. Circulation. 2013; $127: 1485-92$

6. David TE, David CM, Manlhiot C. Simplici-T annuloplasty band for mitral valve repair for degenerative disease. Ann Thorac Surg. 2014;98:1551-6.

7. Zoghbi WA, Enriquez-Sarano M, Foster E, Grayburn PA, Kraft CD, Levine RA, et al. American Society of Echocardiography. Recommendations for evaluation of the severity of native valvular regurgitation with two-dimensional and Doppler echocardiography. J Am Soc Echocardiogr. 2003;16:777-802.

8. Akins CW, Miller DC, Turina MI, Kouchoukos NT, Blackstone EH, Grunkemeier GL, et al. Guidelines for reporting mortality and morbidity after cardiac valve interventions. J Thorac Cardiovasc Surg. 2008;135:732-8.

9. Murashita T, Okada Y, Kanemitsu H, Fukunaga N, Konishi Y, Nakamura K, et al, Fate of functional tricuspid regurgitation after mitral valve repair for degenerative mitral regurgitation. Circ J. 2013;77:2288-94.

10. Yilmaz O, Suri RM, Dearani JA, Sundt TM III, Daly RC, Burkhart HM, et al. Functional tricuspid regurgitation at the time of mitral valve repair for degenerative leaflet prolapse: the case for a selective approach. J Thorac Cardiovasc Surg. 2011;142:608-13.

11. Rajbanshi BG, Suri RM, Nkomo VT, Dearani JA, Daly RC, Burkhart HM, et al. Influence of mitral valve repair versus replacement on the development of late functional tricuspid regurgitation. J Thorac Cardiovasc Surg. 2014;148: 1957-62.

12. Topilsky Y, Nkomo VT, Vatury O, Michelena HI, Letourneau T, Suri RM, et al. Clinical outcome of isolated tricuspid regurgitation. JACC Cardiovasc Imaging. 2014; 7:1185-94.

13. Höke U, Auger D, Thijssen J, Wolterbeek R, van der Velde ET, Holman ER, et al. Significant lead-induced tricuspid regurgitation is associated with poor prognosis at long-term follow-up. Heart. 2014;100:960-8.

14. Ratschiller T, Guenther T, Knappich C, Guenzinger R, Kehl V, Voss B, et al. Do transvalvular pacemaker leads influence functional outcome after tricuspid ring annuloplasty? Eur J Cardiothorac Surg. 2015;48:363-9.

15. Yoo JS, Kim JB, Jung SH, Choo SJ, Chung CH, Lee JW. Impact of the maze procedure and postoperative atrial fibrillation on progression of functional tricuspid regurgitation in patients undergoing degenerative mitral repair. Eur J Cardiothorac Surg. 2013;43:520-5.

16. Dreyfus GD, Corbi PJ, Chan KMJ, Bahrami T. Secondary tricuspid regurgitation or dilatation: which should be the criteria for surgical repair? Ann Thorac Surg. 2005;79:127-32.

17. Nemoto N, Lesser JR, Pedersen WR, Sorajja P, Spinner E, Garberich RF, et al. Pathogenic structural heart changes in early tricuspid regurgitation. J Thorac Cardiovasc Surg. 2015; 150:323-30.

18. Vahanian A, Alfieri O, Andreotti F, Antunes MJ, Barón-Esquivias G, Baumgartner H, et al. Guidelines on the management of valvular heart disease (version 2012). Eur J Cardiothorac Surg. 2012;42:S1-44.

19. Nico R, Van de Veire N, Braun J, Delgado V. Tricuspid annuloplasty prevents right ventricular dilatation and progression of tricuspid regurgitation in patients with tricuspid annular dilatation undergoing mitral valve repair. J Thorac Cardiovasc Surg. 2011:141:1431-9.

20. Badhwar V, Rankin JS, He X, Jacobs JP, Gammie JS, Furnary AP, et al. The Society of Thoracic Surgeons Mitral Repair/Replacement Composite Score: a report of The Society of Thoracic Surgeons Quality Measurement Task Force. Ann Thorac Surg. 2016;101:2265-71.

21. Ling LF, Obuchowski NA, Rodriguez L, Popovic Z, Kwon D, Marwick TH. Accuracy and interobserver concordance of echocardiographic assessment of right ventricular size and systolic function: a quality control exercise. $J \mathrm{Am}$ Soc Echocardiogr. 2012;25:709-13.

22. Sordelli C, Lancellotti P, Carlomagno G, Di Giannuario G, Alati E, De Bonis M, et al. Tricuspid annular size and regurgitation progression after surgical repair for degenerative mitral regurgitation. Am J Cardiol. 2016;118:424-31.

23. Tang GH, David TE, Singh SK, Maganti MD, Armstrong S, Borger MA. Tricuspid valve repair with an annuloplasty ring results in improved long-term outcomes. Circulation. 2006;114(1 suppl):I577-81.

24. Navia JL, Nowicki ER, Blackstone EH, Ling LF, Kittayarak C, Nowicki ER, et al. Surgical management of secondary tricuspid valve regurgitation: annulus, commissure, or leaflet procedure? J Thorac Cardiovasc Surg. 2010;139: $1473-82$.
Key Words: tricuspid insufficiency, tricuspid valve, mitral valve repair, mitral insufficiency

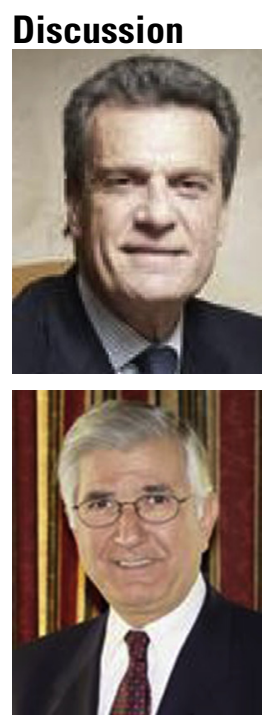

Dr G. Dreyfus (Monte Carlo, Monaco). Dr David, as always, an excellent presentation; however, you told us that tricuspid regurgitation (TR) does not increase with time and unless severe, it is not an issue when performing mitral valve repair, if I did understand well.

Dr David (Toronto, Ontario, Canada). Yes, when we started practicing, only severe TR or in patients with rightsided failure was the tricuspid valve was repaired.

Dr Dreyfus. Well, you would not be surprised if I did say right at the beginning that I disagree with the message that the title of your presentation conveys. But I would like to come back to your presentation.

You are dealing with a series of 1171 patients operated by one single surgeon, and a great surgeon, from 1985 until 2005. So first, your series can clearly be divided into 2 time periods, 1985 until 2005 and another one from 2005 until 2010. Roughly you have about 20 years of 25 where you have not really valid data on the preoperative tricuspid valve and its regurgitation grade. I quote you in your paper:

"In reviewing the echo reports from studies done in the 1980s and the 1990s we found that the TV was frequently overlooked by echocardiographers because their written reports contained no information on functional status of the valve or, simply stated, that the right-side valves were normal without quantification. With time we realized that a few patients developed transient right-side failure during the first couple of weeks after mitral repair and they often had evidence of moderate to severe TR before surgery."

This is probably one of the most important issues of your presentation, as you are telling us that you had no preoperative data concerning the tricuspid valve, and let's hope that you will not tell us that these data were available at the time of surgery under anesthesia, because then you would agree that grading would then become completely irrelevant, even more so for the tricuspid valve than for the mitral valve. So how can you therefore conclude that there is no TR increase as you have no reference point? You did say you had 138 who had moderate severe TR preoperatively but only 55 received an annuloplasty. Why the others did not and what was their outcome?

But overall, can you seriously say from your data that TR is uncommon after mitral valve repair and do you think that your data supports such statements. 
Dr David. The preoperative TR was based on intraoperative transesophageal echocardiography; if the intraoperative transesophageal echo showed no TR, that is how it was coded, but, if anything, we underestimated TR intraoperatively. Likely more patients have TR than reported, according to your argument.

Dr Dreyfus. Yes, of course, you underestimated it, but we do not know really what is the evolution of TR grading if you mix up, first of all, data from 25 years back where the tricuspid valve was not analyzed in the same way as it is today.

Dr David. But only $20 \%$ of the patients died; $80 \%$ survived over 30 years and they had echo afterwards.

Dr Dreyfus. Hold on. Death is another issue.

Dr David. And since 2003 echo was done according to guidelines. So even if they had TR or not before and if they had an echo after that time, what does it matter? The reality is 15 years later only $9 \%$ of patients had isolated TR.

Dr Dreyfus. You showed us a very important slide. You have a table, which is Table 1 in your manuscript, which assigns a grading to the 1171 patients subdivided into none, mild, moderate, and severe. But accordingly to American College of Cardiology/American Heart Association and European Society of Cardiology echo guidelines, only none/mild and severe TR can be identified. Moderate TR is not quantifiable. This is why in our paper from 2005 we stressed that annular dilatation was more relevant than TR grading, and, if I understand well, you have mixed up in this assignment, data from transesophageal echocardiography and data before surgery, which I think from a methodology standpoint is not fair.

It is funny enough to stress that you had about $13 \%$ of patients who showed moderate and/or severe TR, the same number as the Mayo Clinic did, who also denies that it is an ongoing process, the same figure as we had in our paper in 2005 to which you refer. They also had an increase up to $30 \%$ and they said this was not a problem, as you are saying that it is not a problem. It is not a question of data analysis, it is the interpretation of it which seems to be wrong.

Dr David. I don't quite understand your question, because these patients were followed prospectively. They had an echo every 2 or 3 years. Yes, in the 1980s and the 1990s the cardiologists didn't look at the tricuspid valve as they do now. So the reports frequently read normal right side valves. So I assumed that if it's normal there was no severe leakage.

Dr Dreyfus. Sorry, for an average European surgeon or French surgeon, it's difficult to understand. If you enter data and you go back to your data 25 years back you are telling me it is prospective? This is a retrospective analysis. You looked at the echo of the patients 25 years ago. Moreover, you relied on echos performed by referring cardiologists and not according to a core laboratory review. It does indeed weaken your analysis even if prospective.

Dr David. The patients were followed prospectively. I looked back 25 years, but our patients were followed prospectively, not retrospectively. The patients who had mitral valve repair, I saw them at 2 or 3 months, did an echo. The cardiologists continued following every year, had more echoes. They were followed prospectively.

Dr Dreyfus. Okay. Second point. Most likely for statistical purposes you defined as endpoints reoperation and occurrence of more than moderate TR. The main issue is that there is no way to know how many patients had TR and how many did not, especially if reoperations are mixed with moderate severe TR. Similarly, there are no clinical symptoms reported. It is impossible to know whether patients were symptomatic in relation with their TR other than those reoperated.

If I did report, for instance, 2000 coronary bypasses and did tell you that no patients had ischemia, occluded grafts, secondary stents because they did not come back for surgery, basically you would believe me? You are telling this exactly.

Dr David. But that isn't what I am saying. I said there are 5 possible outcomes and I summarized them.

Dr Dreyfus. But why did we mix up reoperation with an increase of TR grading? This is another issue.

Dr David. Wait a second. If you read the manuscript carefully, in the isolated TR, only 2 of them died from TR; they were considered inoperable.

Dr Dreyfus. Hold on. Dying is the ultimate issue. You can have TR; you can have no reoperation and not die. Your paper is that TR is uncommon after mitral valve repair.

Dr David. And it is uncommon.

Dr Dreyfus. You didn't stick to the title. I am not fighting your findings. I am fighting the message that you convey based on your data. You are mixing up reoperation, which is an entity, and not all patients with recurrent mitral regurgitation or TR are being reoperated, and basically as we do not know which are which, tell me how we can know how many patients have developed secondary TR? We can't.

Dr David. We did. I showed you there: $7 \%$ of the entire population developed isolated $\mathrm{TR}$ and $2 \%$ developed recurrent mitral and tricuspid regurgitation. In the slides it was listed as valve-related complications.

Dr Dreyfus. Seven percent is your incidence of annuloplasty.

Dr David. No, I am sorry, no. The annuloplasty incidence was $4.7 \%$. Of those patients, by the way, 30\% developed TR again at 15 years, indicating that tricuspid annuloplasty is not the answer either; it doesn't solve the TR permanently.

Dr Dreyfus. Well, I don't want to get into the tricuspid annuloplasty business, because basically you have used so many different technique over 25 years and did not mention 
or identify the tethering entity, which cannot be treated by annuloplasty alone.

Dr David. Yes, that's correct.

Dr Dreyfus. - that I don't think that it is relevant to talk about surgery, because you have been using De Vega, the Simplici-T, and the rigid or not rigid rings.

Dr David. That's correct.

Dr Dreyfus. So I don't think this is the point. And we are not talking here about surgery. We are talking about the development of TR and whether this disease is a selfperpetuated and ongoing process, and this is what you are negating and this is why I am not in agreement with your message.

Dr David. Gilles, what I am conveying is if you repair a mitral valve and the patient does not have TR before the operation, the chance that they develop TR within 15 years is only 5\%, develop moderate severe. That is all I am saying. If you had TR before the operation, bad news.

Dr Moon. I am going to have to ask you guys to take this out back. I heard some criticism of the paper from Mount Sinai. Is there anyone here from Mount Sinai?

Dr Dreyfus. It's a pity. It's a very constructive discussion. I like the responses of Dr. David. I have not finished, however.

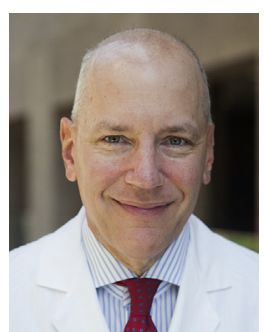

Dr D. Adams (New York, NY). Tirone, it's a pity we didn't have a microphone to record our dinner conversation together last night as we could have played it now. We have been discussing your paper for a while. I said last night I was going to tell everyone that I have always respected you as a master surgeon, but now I know you are a master magician as well. It is "magical" to suggest your analysis is an answer to our paper presented by Joanna Chikwe last year where we described a contemporary series of more than 600 patients treated exactly the same way in the operating room, with a preoperative echo grade of TR not just from the intraoperative transesophageal echocardiography but on preoperative studies, and describing long-term postoperative data on degree of tricuspid regurgitation, functional class, right atrial size, pulmonary hypertension, and the recovery of right ventricular dysfunction.

So I don't think that your retrospective analysis exactly "answers" the paper we presented last year; there are a lot of limitations ... you agree?

Dr David. I agree entirely. Any retrospective analysis has limitations, although the patients were followed prospectively.

Dr Adams. They were followed, Tirone, but as Gilles stated, many cardiologists "lost" in Canada didn't read his paper in 2005 and probably have not read subsequent published papers on functional tricuspid valve disease. So one still wonders, were they really assessing tricuspid valve function postoperatively? We don't really know. The one thing we do know is your patients survived after surgery, right? Survival was not impacted, but you didn't present data on functional class, and we don't know if they will continue to survive. So you don't really know what the impact of moderate or severe TR is on your patients. Agree?

Dr David. Agree. I had 8 minutes to present. I went over a minute to present this paper. The functional class bears no relationship to tricuspid regurgitation. And we have an actuarial in the manuscript. We plotted cumulative functional classes 3 and 4 versus tricuspid regurgitation. Only 2 patients developed heart failure.

Dr Adams. Okay. Tirone, because the moderators are going to cut us off, I just have a few more questions I have to raise. One is, I am going to do your mitral valve repair for degenerative disease. In 4 years would you like an echo that says mild or no TR or one that finds moderate TR?

\section{Dr David. No TR.}

Dr Adams. So we agree that, even though you have not demonstrated a clinical impact of not addressing moderate TR in your patients, you want a more aggressive approach today because you don't want TR after your mitral valve repair. That's why in the conclusion of your manuscript, which you didn't present today, that you now recommend tricuspid repair if you have moderate TR.

Dr David. It was one of the items that moderate TR caused more TR afterwards and it affected survival, so we should repair it, moderate and severe, but not mild. In your paper three-fourths of them had no TR or mild TR.

Dr Adams. Okay, Tirone. So let me ask about a patient in our paper. If you see tomorrow a 65-year-old patient with severe MR, mild TR, right ventricular dilatation, moderate pulmonary hypertension, and ejection fraction of 55\%, and their tricuspid diameter is 45 , are they going to get an operation?

Dr David. Yes, they are.

Dr Adams. Are they going to get a tricuspid repair with mitral repair?

Dr David. Absolutely.

Dr Adams. But they only have mild TR.

Dr David. But the annulus is dilated.

Dr Adams. Exactly, they have other risk factors.

Dr David. They should have tricuspid annuloplasty.

Dr Adams. And this is the take-home message, because you and I have talked a lot about this since last year. Tirone, I just want to summarize that there are a lot of patients who benefit from concomitant tricuspid valve repair, including patients that don't have moderate or severe TR, and that is based on risk factors for progression of disease. So I think that we agree on. We also agree that tricuspid annular dilatation in a Barlow's patient, for example, may be less important than in a patient with a smaller valve and fibroelastic deficiency. Perhaps we have to be more proscriptive in 
certain subgroups we are treating without associated risk factors.

Dr David. Absolutely, and after this paper I will be even more aggressive. Likely it's going to be $12 \%, 15 \%, 20 \%$ of my cases, but never, David, 65.

Dr Adams. That is, again, the real take-home message. You may now repair $25 \%$ to $30 \%$ of functional TR; we are on the way back to $40 \%$ to $50 \%$. We are actually not that far apart in our current thinking. Am I right?

Dr David. I agree.

Dr Moon. I am going to give everybody final words. Thirty seconds.

Dr Dreyfus. Finally, Tirone, I think we do not disagree as much as your title seems to be. We would agree that TR grading is unreliable, that tricuspid annular dilatation is more relevant than grading, and perhaps we need to tailor the indication more than just saying there is some regurgitation and there is an annulus at 40 . You agree with this?

Dr David. I agree entirely and that is why a randomized trial is very timely, particularly regarding size of the annulus.

Dr Dreyfus. And you also agree that you should put some of kind of rigid or semirigid ring and not put bands or stitches or De Vega, because these are prone to fail rapidly?

Dr David. We published this. All our failures were De Vega or flexible bands.

Dr Dreyfus. When do you think we will have the data of your 2005-2010 patients?

Dr David. Next year at this meeting. The manuscript is being prepared.
Dr Dreyfus. Well, there will be no more debate then.

Dr Moon. We have 30 seconds from the United States.

Dr Adams. I enjoyed our discussion. Finally, I want to address your thoughts regarding a randomized trial being discussed in the United States. I think we agree that patients with isolated tricuspid dilatation without other important risk factors are an important population to study. Patients with moderate TR, pulmonary hypertension, right ventricular dilatation or dysfunction, low left ventricular ejection fraction, or atrial fibrillation less interesting to randomize. I don't think you would randomize many of these patient anymore. I am right?

Dr David. I agree. But, David, even in your paper, patients who had a tricuspid annuloplasty did not live as long. It is one single line in your manuscript. But Joanna will tell you this, she did the analysis I guess, that survival in those who had tricuspid annuloplasty was shorter, at seven years, significantly so.

Dr Adams. All the more reason to be aggressive because we were doing tricuspid repair in patients with more significant markers of advanced heart disease. Tirone, we are not saying we can cure them. Maybe their survival would have been even worse if we hadn't treated them.

Dr David. The tricuspid is a bystander. It's the patient.

Dr Adams. Tirone, I am going to see you in a few minutes at the coffee break. We will continue the discussion from dinner last night, to this morning, and I am sure for a long time to come. 
TABLE E1. Variables examined for entry into risk models

Variable examined for entry into risk models

Percent imputed

Year of operation

$0.0 \%$

Age at operation (y)

$0.0 \%$

Sex

$0.0 \%$

Previous cardiac intervention

Elective (vs urgent) procedure

Preoperative angina/myocardial infarction

$0.0 \%$

Preoperative NYHA class

$0.0 \%$

Preoperative LV grade

$0.1 \%$

$(<20 \%, 20 \%-39 \%, 40 \%-59 \%, \geq 60 \%)$

Preoperative atrial fibrillation

$0.1 \%$

Preoperative congestive heart failure

$0.0 \%$

$0.0 \%$

$0.0 \%$

Preoperative hyperlipidemia

$0.0 \%$

Preoperative stroke/transient ischemic attack

$0.1 \%$

Smoking history

Family history of coronary artery disease

$0.0 \%$

Preoperative endocarditis

$0.0 \%$

$0.0 \%$

Coronary artery disease

$6.9 \%$

$2.7 \%$

Preoperative TR grade*

$\begin{array}{lr}\text { Size of the mitral valve annulus }(\mathrm{mm}) \dagger & 10.8 \% \\ \text { Type of mitral valve prosthesis } \dagger & 0.0 \%\end{array}$

Concomitant tricuspid annuloplasty $\dagger \quad 0.0 \%$

Concomitant maze procedure $\dagger \quad 0.0 \%$

Postoperative atrial fibrillation $\quad 0.0 \%$

(up to hospital discharge) $\dagger$

Postoperative pacemaker insertion $\quad 0.0 \%$

(up to hospital discharge) $\dagger$

Postoperative MR grade ( $<1$ mo after procedure $) \dagger \quad 3.6 \%$

Postoperative TR grade ( $<1$ mo after procedure $) \dagger \quad 3.6 \%$

NYHA, New York Heart Association; $L V$, left ventricular; $T R$, tricuspid regurgitation; $M R$, mitral regurgitation. *Not included in models for preoperative TR grade. $\dagger$ Included only in models of long-term outcomes. 